\title{
Designed for Dentistry, Articaine in NLC Improves Anaesthesia at Inflamed Tissues
}

\author{
Gustavo H. Rodrigues da Silva ${ }^{1,3}$, Julia B. P. Lemes², Gabriela Geronimo', Iola F. Duarte ${ }^{3}$, Carlos A. \\ Parada $^{2}$, Eneida de Paula ${ }^{1}$ \\ ${ }^{1}$ Department of Biochemistry and Tissue Biology, Institute of Biology, University of Campinas - UNICAMP, Campinas - \\ SãoPaulo, Brazil.g008839@dac.unicamp.br; g.gabriela1995@hotmail.com; depaula@unicamp.br \\ ${ }^{2}$ Department of Structural and Functional Biology, Institute of Biology, University of Campinas, Campinas, São Paulo, \\ Brazil.juliabplemes@gmail.com; parada@unicamp.br \\ ${ }^{3} \mathrm{CICECO}-$ Aveiro Institute of Materials, Department of Chemistry, University of Aveiro, Aveiro, Portugal \\ ioladuarte@ua.pt.
}

\begin{abstract}
Although used on a regular basis, local anaesthetics fail in places where inflammation is present, a problem for routine dental care. Intrinsic factors of the inflammatory process prevent anaesthetics from performing their function, at safe doses. The encapsulation of local anaesthetics in nanostructured lipid carriers (NLC) produces formulations with good physicochemical characteristics and improved anaesthetic effect. In that sense we developed an NLC formulation for articaine (ATC), a local anaesthetic with increasing use in dentistry. The developed formulation showed average particle sizes of $237.6 \pm 3.3 \mathrm{~nm}$, low polydispersity (PDI=0.169 \pm 0.015 ) and negative zeta potentials $(-42.1 \pm 0.5 \mathrm{mV})$, suitable for parenteral application. ATC was successfully encapsulated $(\% \mathrm{EE}=66.8 \pm 2.3 \%)$ in such lipid nanocarriers. When tested in vivo, in a rodent carrageenan-induced inflammation model, NLC-ATC decreased by $35 \%$ the inflammatory hyperalgesia response, in relation to free articaine. These results had encouraged us to propose further clinical evaluation tests to test the formulation in dentistry.
\end{abstract}

Keywords: Nanostructured lipid carriers, articaine, inflammatory pain, anaesthesia failure, dentistry.

\section{Introduction}

Local anaesthetic (LA) failure or a lower degree of analgesia often occurs in inflamed tissues, especially in dental procedures when a pulpitis or periodontitis process is installed [1]. In case of pulpitis there are reports of alveolar nerveanaesthetic failure in $c a .30-45 \%$ of cases [2,3]. The proposed mechanism for anaesthetic failure is that the acidic environment of inflamed tissues (reduction of up to $1 \mathrm{pH}$ unit $[4,5]$ ) reduces the potency of LA [1, 6, 7]. In general, the pKa of local anaesthetics is greater than 7.5. In case of acidosis, a larger fraction of LA turns out to be ionized (charged), decreasing its interaction with excitable membranes [1,8]. Thus, the ineffective therapeutic activity would be due to the lack of neutral LA species, of greater solubility in biological membranes where the voltage-gated sodium channel is located. Another claimed mechanism for anaesthetic failure involves the hypersensitization of neurons, caused by inflammatory mediators, resulting in a process called hyperalgesia $[9,6]$. In both cases it would be necessary to increase the LA concentration (by injecting a larger volume) to achieve the desired antinociceptive action. However, the safety dose of LA is limited, and the use of a higher doses increases the risk of systemic toxicity mainly to cardiovascular and central nervous systems [10].

Nanostructured lipid carriers (NLC) are drug delivery systems developed in the early 1990s as an alternative to emulsions, liposomes and polymeric nanoparticles [11]. These nanoparticles are composed of a (blend of solid and liquid) lipid matrix plus a surfactant shell. NLC are excellent carriers for LA, being able to prolong the anaesthesia time, as reported for different agents, mainly at topical administration [2,13-15]. Local anaesthetics can be encapsulated into the lipid core of NLC in the poorly water-soluble, neutral (uncharged) form so that these formulations, unlike the commercial injectable LA formulas, have a $\mathrm{pH}$ above 7 [12].

Articaine (ATC) has become increasingly popular, especially in dental practice, since it was launched in the marked, in 1984 [13,14]. ATC is the only aminoamide LA with a thiophene lipophilic moiety [15] and its low half-life in the bloodstream due to rapid hydrolysis $(20 \mathrm{~min})$ allows the reduction of systemic toxicity compared to other LA [16]. Literature 
shows that the use of ATC slightly increase the anaesthetic efficacy in cases of pulp inflammation [17, 18]. Thus, we decided to prepare an ATC-in-NLC formulation in order to control the drug release at the site of action and promote superior anaesthesia. To test the antinociceptive effect, we used the carrageenan inflammatory hyperalgesia model, comparing the differences between free and encapsulated articaine.

\section{Materials and methods}

\section{1. Materials}

Articaine hydrochloride (ATC) was donated by DFL Ind. Com. S.A. (Brazil). $\lambda$-Carrageenan was purchased from Sigma-Aldrich. Deionized water (18 M $\Omega$ ) was obtained with an Elga USF Maxima ultra-pure water purifier.

\section{2. Formulation preparation}

The emulsification-ultrasonication method [12] was used to prepare the NLC. Briefly, the mixture of synthetic lipids (white waxy solid ester with a triglyceride) and the base form of articaine were melted in a water bath, at $65^{\circ} \mathrm{C}$. A solution of surfactant was heated to the same temperature and both phases were mixed under high-speed agitation $(10,000 \mathrm{rpm})$, for $3 \mathrm{~min}$ in an Ultra-Turrax blender (IKA WerkeStaufen, Germany). The mixture was then sonicated for 15 min, in a Vibracell tip sonicator (Sonics \& Mat. Inc., Danbury, USA) operated at $500 \mathrm{~W}$ and $20 \mathrm{kHz}$, in alternating $30 \mathrm{~s}$ (on/off) cycles. To form the NLC, the resultant nanoemulsion was immediately cooled down to room temperature, with an ice bath.

\section{3. Characterization of formulations}

\section{3. 1. Physical chemical characterization}

A Nano ZS90 analyser (Malvern Instruments, UK) was used to determine the nanoparticles size and polydispersity index (PDI) by dynamic light scattering (DLS), as well as their zeta potential (ZP) by laser doppler microelectrophoresis [12]. Samples were diluted $500 \mathrm{x}$ and measured in triplicates.

\section{3. 2. Articaine quantification and encapsulation efficiency (\%EE)}

A Waters Breeze 2 (Waters Co. Milford, MA, USA) high performance liquid chromatography equipment was used, with a Gemini ${ }^{\circledR} 5 \mu \mathrm{m}, \mathrm{C} 18,110 \AA$ A, with 150 x $4.6 \mathrm{~mm}$ (Phenomenex ${ }^{\circledR}$, Torrance, USA) column, at $40{ }^{\circ} \mathrm{C}$. The mobile phase at $1 \mathrm{~mL} / \mathrm{min}$ flux was a mixture of acetonitrile: $\mathrm{KH}_{2} \mathrm{PO}_{4} 50 \mathrm{mM}(25: 75$, v/v). The injection volume was $30 \mu \mathrm{L}$ and the absorbance was followed at $273 \mathrm{~nm}$ [19]. The total amount of ATC $\left(\mathrm{ATC}_{\text {total }}\right)$ in the formulations was determined by diluting the samples in the mobile phase $(n=3)$ [20]. The encapsulation efficiency (\%EE) was determined by the ultrafiltrationcentrifugation method, using $30 \mathrm{kDa}$ (Millipore) cellulose filters. The concentration of ATC in the filtrate $\left(\mathrm{ATC}_{\text {free}}\right) \mathrm{was}$ measured and \%EE was calculated according to eq. 1 [20]:

$$
\% E E=\frac{A T C_{\text {total }^{-}} A T C_{\text {free }}}{A T C_{\text {total }}} x 100
$$

\section{4. In vivo test}

\section{4. 1. Animal Care}

Adult male Wistar (Rattus novegicus albinus) rats (250-350 g) were obtained from Centro de Bioterismo (CEMIB/UNICAMP). The experimental protocol was approved by the UNICAMP Institutional Animal Care and Use Committee (protocol \#4832-1), which follows the recommendations of the Guide for the Care and Use of Laboratory Animals. Rats were housed in groups of 4, in a 12/12 h light/dark cycle. All animal procedures were conducted in accordance to the rules established by IASP (International Association for the Study of Pain). 


\section{4. 3. Carrageenan inflammatory hyperalgesia model}

The rats $(n=6)$ received a single intraplantar injection of $\lambda$-Carrageenan $(100 \mu \mathrm{g} / 50 \mu \mathrm{L} / \mathrm{paw})$. The mechanical nociceptive threshold was measured by electronic von Frey method at basal conditions (before inflammatory stimulation) stimulation) and at times of 1, 2, 3, 4, 5 and $6 \mathrm{~h}$ post-carrageenan application. The samples: saline, $0.5 \%$ ATC, $0.5 \%$ ATC in ATC in NLC (NLC-ATC) and NLC without articaine $\left(\mathrm{NLC}_{\mathrm{ctrl}}\right)$ were intraplantar injected 170 min after carrageenan administration.

\section{4. 2. Electronic von Frey test}

The mechanical nociceptive threshold was measured by the von Frey method [21]. Previously, rats were adapted in a quiet room and placed in acrylic cages $(12 \times 20 \times 17 \mathrm{~cm})$ with wire grid floors. For acclimation, the animals were maintained at the cages for 15-30 min before testing. A tilted mirror placed under the grid was used to provide a clear view of rat hind paw. The test consisted of inducing the hind paw flexion reflex using a polypropylene tip $\left(0.7 \mathrm{~mm}^{2}\right)$ connected to hand-held force transducer (Electronic Analgesimeter, Insight ${ }^{\circledR}$, Brazil). The investigator was trained to apply the tip in the central region of the paw, between the five distal footpads, and gradually increase pressure. The stimulus was automatically discontinued when rat showed the paw withdrawal reflex. At this point the intensity of force (grams) was recorded. Three stimuli were performed at the same paw to obtain the average of response. Animals were tested before and after treatment with one of the samples. The data were expressed by $\Delta$ (delta) of mechanical threshold (grams), calculated by subtracting the average of the three measurements after treatment, from the average measurements before treatment.

\section{Results and Discussion}

For the development of the NLC using factorial design (data not shown), the formulation with the smallest possible average particle size and polydispersity was chosen, as recommended for parenteral administration [22]. Table 1 shows the measured parameters of the optimized articaine NLC formulation (NLC-ATC) and its control, prepared without articaine $\left(\mathrm{NLC}_{\mathrm{ctrl}}\right)$. The NLC with and without articaine did not significantly differ in size, and the low PDI value $(<0.2)$ of NLCATC attested the monodisperse distribution of particle sizes [23]. The magnitude of zeta potentials ( $>20 \mathrm{mV}$ in modulus) revealed nanoparticles with a good degree of electrostatic repulsion and stability [24]. The \%EE value revealed that most of ATC (> 66\%) got entrapped into the lipid core of the NLC, in agreement with results reported for the encapsulation of other aminoamide LA in NLC [25-27]. Thus, these results are predictive of a sustained release of ATC at the site of action, protection from systemic metabolism and possible prolonged anaesthetic effect.

Table 1: Physicochemical parameters of the optimized nanostructured lipid carrier formulation (NLC-ATC) and its control, prepared without articaine $\left(\mathrm{NLC}_{\mathrm{ctrl}}\right)$ : average diameters (size), polydispersity index (PDI), zeta potential $(\mathrm{mV})$ and encapsulation efficiency $(\% \mathrm{EE})$

\begin{tabular}{|c|c|c|c|c|}
\hline Formulation & $\begin{array}{c}\text { Size } \\
(\mathbf{n m})\end{array}$ & PDI & $\begin{array}{c}\text { zeta potential } \\
(\mathbf{m V})\end{array}$ & \%EE \\
\hline NLC-ATC & $237.6 \pm 3.3$ & $0.169 \pm 0.015$ & $-42.1 \pm 0.5$ & $66.8 \pm 2.3$ \\
\hline NLC $_{\text {ctrl }}$ & $236.0 \pm 2.9$ & $0.205 \pm 0.011$ & $-30.5 \pm 0.4$ & - \\
\hline
\end{tabular}

$\lambda$-Carrageenan, a linear sulphated polysaccharide extracted from red edible seaweeds, induces a highly reproducible, nonimmune acute inflammation when injected in the paw of rats. Thus, it is commonly used to induce inflammation, displaying all cardinal signs of inflammation (oedema, hyperalgesia, erythema) immediately after subcutaneous injection [28]. Moreover, the hyperalgesia (exacerbated sensitivity to thermal and mechanical stimuli) provoked by carrageenan, makes it appropriate for the study inflammatory pain [29]. Two phases of inflammation are induced by $\lambda$-carrageenan: the first - that occurs within an hour of injection - that is associated with histamine, serotonin and bradykinin liberation, and the second - from 1-3 or more hours - characterized by prostaglandin production [30].

In this study we measured signs of mechanical hyperalgesia throughout the inflammatory process (from 1 to 6 h; Figure 1A) to notice that the peak of pain occurred after $3 \mathrm{~h}$ of carrageenan injection (control), when all inflammatory mediators were present (Figure 1B). For this reason, the formulations were injected $10 \mathrm{~min}$ before the peak of pain (Figure 1A). The 
solution of free articaine was tested in different concentrations (data not shown). Then, the concentration of $0.5 \%$ was chosen because allowed visualization of a significant difference in anaesthesia regarding the control group, without causing total loss of pain sensation.

The behavioural assessment showed that the treatment of free articaine (ATC) promoted a significant decrease of mechanical hyperalgesia induced by carrageenan at the third hour, in comparison to the group control (Carrageenan + Saline). For encapsulated articaine (NLC-ATC) the data showed a significant and longer reduction in hyperalgesia when compared to the control group. Also, there was a significant decrease of pain (35\%) in relation to rats treated with ATC, suggesting an improvement in analgesia with the nanoparticulated system. At the fourth hour of evaluation the analgesic effect still remained in the group NLC-ATC unlike the free-articaine solution which had short action. As expected, the group that received the nanoparticle without articaine $\left(\mathrm{NLC}_{\mathrm{ctrl}}\right)$ did not show any difference in relation to the control group. Although the $\lambda$-carrageenan has a standard painful response in rodent, we observed a small (non-significant) difference between the groups at times 1 and 2 hours. This difference is probably a variation caused by the gelatinous consistency of the NLC formulation that affected the intraplantar injection, but it did not interfere in the results of hyperalgesia analysis.

The ability to prolong the anaesthetic effect has been previously reported for LA encapsulated in NLC, with different analgesia tests $[12,26,27]$ but never in a model of peripheral inflammatory pain. Thus, the prolonged release of articaine from the NLC system explains this outstanding effect.

A)
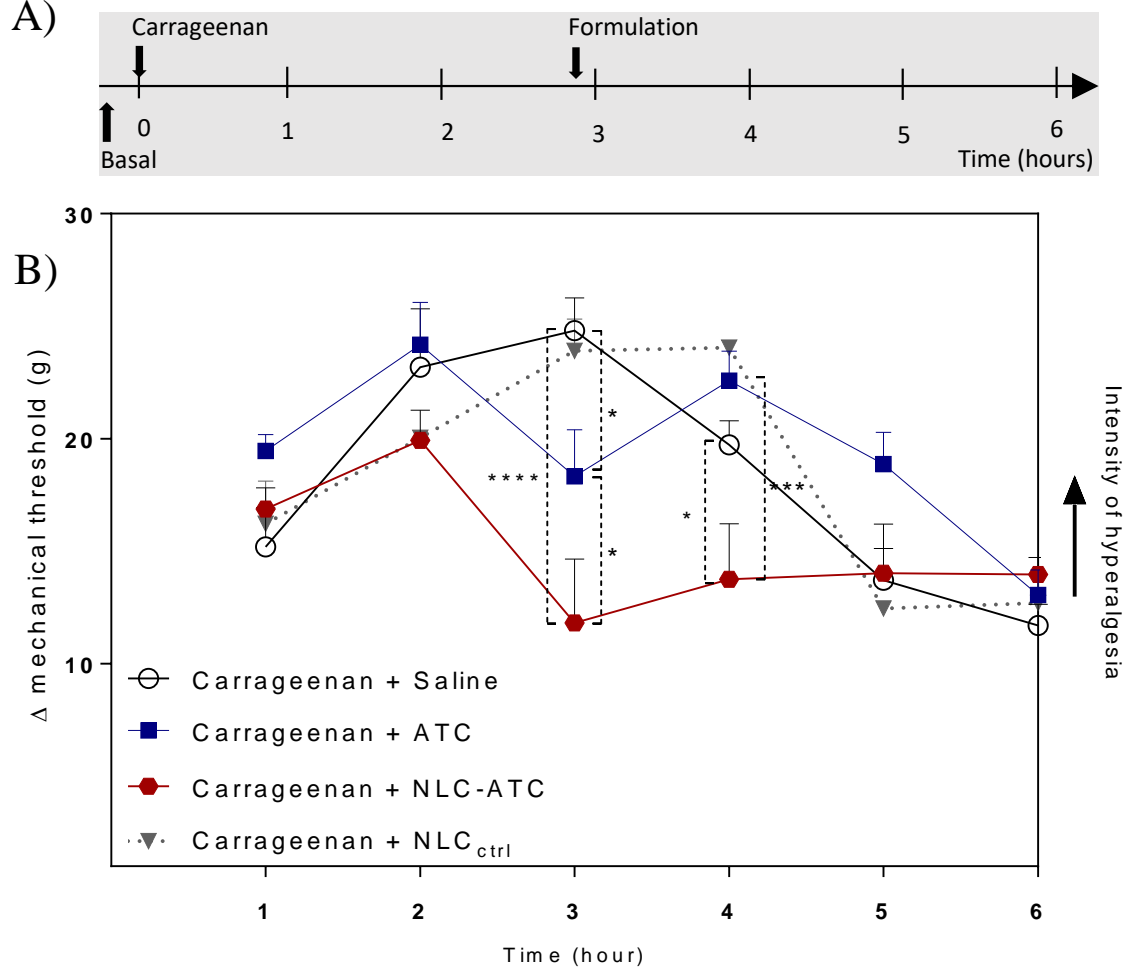

Fig. 1: In vivo carrageenan inflammation model. A) timeline of the experimental design; B) Mechanical nociceptive threshold measured by electronic von Frey test, after treatment with saline solution (control), $0.5 \%$ articaine in solution (ATC) or encapsulated into the NLC (NLC-ATC) and NLC without articaine $\left(\mathrm{NLC}_{\mathrm{ctrl}}\right)$. Statistical analysis: One-way ANOVA plus Tukey-Kramer post hoc. ${ }^{*} \mathrm{p}<$

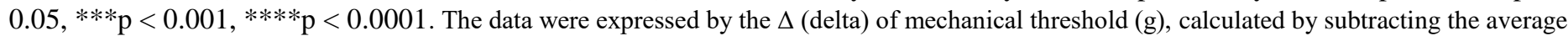
of the three measurements after treatment, from the average measurements before treatment (basal). 
Among the advantages of encapsulating local anaesthetics in NLC, the sustained release is responsible for the increase in analgesia time [31]. Additionally, high doses may be applied without causing systemic toxicity because the drug remains longer at the site of injection. Also related to this, NLC has the ability to protect the encapsulated drug against systemic degradation [32]. These features of NLC-ATC would be of interest in cases of inflammatory hyperalgesia, that requires higher LA doses at the site of injection. Another attribute of nanoparticulated systems is their internalization by the cells [33]. In inflamed tissues, where tissue acidosis increases protonation and reduces LA partition into the membranes, internalization of the entire nanoparticle by the cells could offer another route for the anaesthetic to bind the inactivation gate of the sodium channel, that is located at the cytoplasmic site of the membrane [34]. Altogether these attributes of the lipidbased nanoparticulated system explain the ability of NLC-ATC to increase anaesthesia in inflamed tissues. Besides, although speculative, Fig. 1 shows that free articaine (ATC) produced an increase in pain at times 4-5 post carrageenan injection (i.e. 1-2 $\mathrm{h}$ after ATC administration) that could be explained by the low $\mathrm{pH}$ (3.5-4.0) of the hydrochloride solution; this acidosis, together with the inflammatory process, explain the hyperalgesia. Similar hyperalgesia effect was observed with control NLC $\left(\mathrm{NLC}_{\mathrm{ctrl}}, \mathrm{pH} \sim 5.0-6.0\right) 4$ hours post carrageenan injection. In a different way, the $\mathrm{pH}$ of NLC-ATC formulation (7.5-8.0) is close to the pKa of articaine (7.8 [31]) so that half of the molecules are in the neutral form, of higher partition into the membranes, explaining the more effective anaesthesia effect. Thus, articaine encapsulation in NLC shows promising for application in the treatment of inflammatory pain in dentistry. Nevertheless, further tests should be conducted, to evaluate other pharmacological parameters, before its use in humans.

\section{Conclusion}

Anaesthesia failure in cases of inflammation is a great challenge to be overcome in dentistry. In this work, the potential of nanotechnology application to solve this problem was demonstrated in vivo. Nanostructured lipid carriers loaded with articaine showed good physicochemical features for parenteral application and high encapsulation efficiency. When applied in a carrageenan-induced pain model, the nanometric system significantly reduced the inflammatory pain (35\%) and prolonged the anaesthesia time in comparison to ATC in solution. This result points it out as a candidate for further clinical trials aiming the control of inflammatory pain in dentistry. NLC-ATC provided higher amounts of articaine at the site of action, the presence of uncharged ATC species (due to the $\mathrm{pH}$ of the formulation) and possibly another route for anaesthetic delivery inside the cell (by internalization of the nanoparticle by the nerve membrane).

\section{Acknowledgements}

We thank the Brazilian funding agencies: FAPESP (grant \#14/14457-5; and G.H.R.S. fellowship \#18-24814-0) and CNPq (E.P. fellowship) for the financial support, and DFL Ind. Com. S.A. for kindly providing articaine.

\section{References}

[1] T. Ueno, H. Tsuchiya, M. Mizogami, and K. Takakura, "Local anesthetic failure associated with inflammation: verification of the acidosis mechanism and the hypothetic participation of inflammatory peroxynitrite.," J. Inflamm. Res., vol. 1, pp. 41-8, 2008.

[2] H. P. Cohen, B. Y. Cha, and L. S. W. Spångberg, "Endodontic anesthesia in mandibular molars: A clinical study," J. Endod., vol. 19, no. 7, pp. 370-373, 1993.

[3] I. Potocnik and F. Bajrović, "Failure of inferior alveolar nerve block in endodontics," Endod. Dent. Traumatol., vol. 15, no. 6, pp. 247-51, 1999.

[4] A. Punnia-Moorthy, "Evaluation of $\mathrm{pH}$ changes in inflammation of the subcutaneous air pouch lining in the rat, induced by carrageenan, dextran and Staphylococcus aureus," J. Oral Pathol., vol. 16, no. 1, pp. 36-44, 1987.

[5] D. de Backer, "Lactic acidosis," Minerva Anestesiol., vol. 69, no. 4, pp. 281-284, 2003.

[6] J. G. Meechan, "anaesthesia: How to overcome failed local anaesthesia," Br. Dent. J., vol. 186, no. 1, pp. 15-20, 1999.

[7] D. E. Becker and K. L. Reed, "Local Anesthetics: Review of Pharmacological Considerations," Anesth. Prog., vol. 59, no. 2, pp. 90-102, 2012. 
[8] T. Ueno, M. Mizogami, K. Takakura, and H. Tsuchiya, "Peroxynitrite affects lidocaine by acting on membraneconstituting lipids," J. Anesth., vol. 22, no. 4, pp. 475-478, 2008.

[9] A. P. C. Rocha, D. C. Kraychete, L. Lemonica, L. R. de Carvalho, G. A. M. de Barros, J. B. dos S. Garcia, and R. K. Sakata, "Dor: aspectos atuais da sensibilização periférica e central," Rev. Bras. Anestesiol., vol. 57, no. 1, pp. 94105, 2007.

[10] G. J. Grant, J. Lax, L. Susser, M. Zakowski, T. E. Weissman, and H. Turndorf, "Wound infiltration with liposomal bupivacaine prolongs analgesia in rats," Acta Anaesthesiol Scand, vol. 41, no. 2, pp. 204-207, 1997.

[11] J. Pardeike, A. Hommoss, and R. H. Müller, "Lipid nanoparticles (SLN, NLC) in cosmetic and pharmaceutical dermal products," Int. J. Pharm., vol. 366, no. 1-2, pp. 170-184, 2009.

[12] G. H. Rodrigues da Silva, L. N. M. Ribeiro, H. Mitsutake, V. A. Guilherme, S. R. Castro, R. J. Poppi, M. C. Breitkreitz, and E. de Paula, "Optimised NLC: a nanotechnological approach to improve the anaesthetic effect of bupivacaine," Int. J. Pharm., vol. 529, no. 1-2, pp. 253-263, 2017.

[13] S. H. A. Kakroudi, S. Mehta, and B. J. Millar, "Articaine hydrochloride: is it the solution?," Dent. Update, vol. 42, no. 1, pp. 88-90,92-93, 2015.

[14] G. Bartlett and J. Mansoor, "Articaine buccal infiltration vs lidocaine inferior dental block - a review of the literature," Bdj, vol. 220, no. 3, pp. 117-120, 2016.

[15] G. R. Seward, Handbook of local anesthesia, vol. 9, no. 4. Elsevier, 1981.

[16] O. Onal, A. O. Saltali, and S. Apiliogullari, "Comments on 'Local Anesthetic Systemic Toxicity," Aesthetic Surg. J., vol. 36, no. 1, pp. NP37-NP37, 2016.

[17] M. R. F. P. Monteiro, F. C. Groppo, F. Haiter-Neto, M. C. Volpato, and J. F. A. Almeida, “4\% articaine buccal infiltration versus $2 \%$ lidocaine inferior alveolar nerve block for emergency root canal treatment in mandibular molars with irreversible pulpits: a randomized clinical study," Int. Endod. J., vol. 48, no. 2, pp. 145-152, 2015.

[18] M. C. Peters and T. M. Botero, "In Patients With Symptomatic Irreversible Pulpitis, Articaine is 3.6 Times More Efficacious Than Lidocaine in Achieving Anesthetic Success When Used for Supplementary Infiltration After Mandibular Block Anesthesia," J. Evid. Based. Dent. Pract., vol. 17, no. 2, pp. 99-101, 2017.

[19] H. Al-Mahalawy, H. Abuohashish, S. Chathoth, N. Al-Masoud, and B. Al-Jandan, "Articaine Versus Lidocaine Concentration in the Palatal Tissues After Supraperiosteal Buccal Infiltration Anesthesia," J. Oral Maxillofac. Surg., vol. 76, no. 2, pp. 315.e1-315.e7, 2018.

[20] G. H. R. Da Silva, L. N. de Morais Ribeiro, V. A. Guilherme, S. R. de Castro, M. C. Breitkreitz, and E. de Paula, "Bupivacaine (S75:R25) Loaded in Nanostructured Lipid Carriers: Factorial Design, HPLC Quantification Method and Physicochemical Stability Study," Curr. Drug Deliv., vol. 15, no. 3, pp. 388-396, 2017.

[21] G. G. Vivancos, W. A. Verri, T. M. Cunha, I. R. S. Schivo, C. A. Parada, F. Q. Cunha, and S. H. Ferreira, "An electronic pressure-meter nociception paw test for rats," Brazilian J. Med. Biol. Res., vol. 37, no. 3, pp. 391-399, 2004.

[22] S. Doktorovová, A. B. Kovačević, M. L. Garcia, and E. B. Souto, "Preclinical safety of solid lipid nanoparticles and nanostructured lipid carriers: Current evidence from in vitro and in vivo evaluation," Eur. J. Pharm. Biopharm., vol. 108, pp. 235-252, 2016.

[23] R. H. Müller, K. Mäder, and S. Gohla, "Solid lipid nanoparticles (SLN) for controlled drug delivery,” Eur. J. Pharm. Biopharm., vol. 50, no. 1, pp. 161-77, 2000.

[24] F. Han, S. Li, R. Yin, H. Liu, and L. Xu, "Effect of surfactants on the formation and characterization of a new type of colloidal drug delivery system: Nanostructured lipid carriers," Colloids Surfaces A Physicochem. Eng. Asp., vol. 315, no. 1-3, pp. 210-216, 2008.

[25] G. H. R. Da Silva, L. N. de Morais Ribeiro, V. A. Guilherme, S. R. de Castro, M. C. Breitkreitz, and E. de Paula, "Bupivacaine (S75:R25) Loaded in Nanostructured Lipid Carriers: Factorial Design, HPLC Quantification Method and Physicochemical Stability Study," Curr. Drug Deliv., vol. 15, no. 3, pp. 388-396, 2017.

[26] L. N. M. Ribeiro, M. Franz-Montan, M. C. Breitkreitz, A. C. S. Alcântara, S. R. Castro, V. A. Guilherme, R. M. Barbosa, and E. de Paula, "Nanostructured lipid carriers as robust systems for topical lidocaine-prilocaine release in 
dentistry," Eur. J. Pharm. Sci., vol. 93, pp. 192-202, 2016.

[27] L. N. M. Ribeiro, M. C. Breitkreitz, V. A. Guilherme, G. H. R. da Silva, V. M. Couto, S. R. Castro, B. O. de Paula, D. Machado, and E. de Paula, "Natural lipids-based NLC containing lidocaine: from pre-formulation to in vivo studies," Eur. J. Pharm. Sci., vol. 106, no. in press, pp. 102-112, 2017.

[28] M. H. Napimoga, G. R. Souza, T. M. Cunha, L. F. Ferrari, J. T. Clemente-Napimoga, C. A. Parada, W. A. Verri, F. Q. Cunha, and S. H. Ferreira, "15d-Prostaglandin J2 Inhibits Inflammatory Hypernociception: Involvement of Peripheral Opioid Receptor," J. Pharmacol. Exp. Ther., vol. 324, no. 1, pp. 313-321, 2007.

[29] F. Nantel, D. Denis, R. Gordon, A. Northey, M. Cirino, K. M. Metters, and C. C. Chan, "Distribution and regulation of cyclooxygenase-2 in carrageenan-induced inflammation," Br. J. Pharmacol., vol. 128, no. 4, pp. 853-859, 1999.

[30] K. R. Patil and C. R. Patil, "Anti-inflammatory activity of bartogenic acid containing fraction of fruits of Barringtonia racemosa Roxb. in acute and chronic animal models of inflammation," J. Tradit. Complement. Med., vol. 7, no. 1, pp. 86-93, 2017.

[31] D. R. de Araújo, L. N. de M. Ribeiro, and E. de Paula, "Lipid-based carriers for the delivery of local anesthetics," Expert Opin. Drug Deliv., vol. 16, no. 7, pp. 701-714, 2019.

[32] P. Severino, T. Andreani, A. S. Macedo, J. F. Fangueiro, M. H. a Santana, A. M. Silva, and E. B. Souto, "Current State-of-Art and New Trends on Lipid Nanoparticles (SLN and NLC) for Oral Drug Delivery.," J. Drug Deliv., vol. 2012, p. 750891, 2012.

[33] L. A. B. Ferreira, A. Radaic, G. O. Pugliese, M. B. Valentini, M. R. Oliveira, and D. J. M. B, "Endocitose e tráfego intracelular de nanomateriais Endocytosis and intracellular trafficking of nanomaterials," Acta Farm. Port., vol. 3, pp. 149-166, 2014.

[34] A. Scholz, "Mechanisms of (local) anaesthetics on voltage-gated sodium and other ion channels," Br. J. Anaesth., vol. 89, no. 1, pp. 52-61, 2002. 